\title{
Case-only study of interactions between metabolic enzymes and smoking in colorectal cancer Chunhong Fan ${ }^{1,2}$, Mingjuan Jin1, Kun Chen*1, Yongjing Zhang1, Shuangshuang Zhang ${ }^{1}$ and Bing Liu ${ }^{1}$
}

\author{
Address: ${ }^{1}$ Department of Epidemiology \& Health Statistics, School of Public Health, Zhejiang University, Hangzhou 310058, Zhejiang, China and \\ 2Zhejiang Medical College, Hangzhou 310053, Zhejiang, China \\ Email: Chunhong Fan - happydou_8@hotmail.com; Mingjuan Jin - jinmj@zju.edu.cn; Kun Chen* - ck@zju.edu.cn; \\ Yongjing Zhang - mayun_zyj@163.com; Shuangshuang Zhang - qtss124@sina.com; Bing Liu - Liubing7362@sohu.com \\ * Corresponding author
}

Published: 30 June 2007

BMC Cancer 2007, 7:115 doi:10.1186/147/-2407-7-1/5
Received: 5 February 2007

Accepted: 30 June 2007

This article is available from: http://www.biomedcentral.com/I47I-2407/7//I5

(C) 2007 Fan et al; licensee BioMed Central Ltd.

This is an Open Access article distributed under the terms of the Creative Commons Attribution License (http://creativecommons.org/licenses/by/2.0), which permits unrestricted use, distribution, and reproduction in any medium, provided the original work is properly cited.

\begin{abstract}
Background: Gene-gene and gene-environment interactions involved in the metabolism of carcinogens may increase the risk of cancer. Our objective was to measure the interactions between common polymorphisms of P450 (CYPIA2, CYPIBI, CYP2EI), GSTMI and TI, SULTIAI and cigarette smoking in colorectal cancer (CRC).

Methods: A case-only design was conducted in a Chinese population including 207 patients with sporadic CRC. Unconditional logistic regression analysis was performed adjusting for age, gender, alcohol consumption, and cigarette smoking.

Results: The interaction odds ratio (COR) for the gene-gene interaction between CYPIBI I294G and SULTIAI 638A allele was 2.68 (95\% Cl: 1.16-6.26). The results of the gene-environment analyses revealed that an interaction existed between cigarette smoking and the CYPIBI I294G allele for CRC (COR $=2.62,95 \% \mathrm{Cl}$ : I.0I-6.72), the COR for the interaction of CYPIBI I294G and smoking history $>35$ pack-years was 3.47 ( $95 \% \mathrm{Cl}$ : I.12-10.80). No other significant gene-gene and gene-environment interactions were observed.

Conclusion: Our results showed that the interaction between polymorphisms in CYPIBI I294G and SULTIAI*2 may play a significant role on CRC in the Chinese population. Also, it is suggested that the association between cigarette smoking and CRC could be differentiated by the CYPIBI I294G allele.
\end{abstract}

\section{Background}

Colorectal cancer (CRC) is the third most common malignant tumor, (after lung and breast cancer) worldwide [1]. It has been estimated that there were about 1 million new cases in 2002. China is a nation with relatively low incidence of CRC, being the fifth or sixth most common cause of cancer death in the country. Recently however, the inci- dence rate of CRC has been increasing rapidly in China [2]. The etiology of CRC is likely to be multifaceted. About $5 \%-10 \%$ of CRC can be attributed to inherited high-penetrance genes; the other $90 \%$ may be attributed to diet, lifestyle factors and low-penetrance genes $[3,4]$. Tobacco smoking is a potential risk factor for CRC $[3,5-7]$. The burning of tobacco produces a wide variety of carcino- 
gens, including aromatic amines (AAs), heterocyclic amines (HAAs), polycyclic aromatic hydrocarbons (PAHs) and N-nitroso compounds which are metabolized by some Phase I and Phase II metabolic enzymes, such as cytochrome P450s, glutathione S-transferases (GSTs) and sulfotransferases (SULTs) etc. Many of these enzymatic genes are polymorphic and can affect metabolic capabilities, which may result in a differential susceptibility to CRC.

A number of cytochrome P450s, including CYP1A2 and CYP1B1, are involved in the activation of AAs and HAAs $[8,9]$, while CYP2E1 is an ethanol inducible enzyme involved in the activation of $\mathrm{N}$-nitrosamines. A single base $\mathrm{C}$ to A change in intron 1 at position 734 downstream was the first identified polymorphism of the CYP1A2 gene, and the AA genotype may be associated with increased activity of the enzyme [10]. The Leu432Val amino acid substitution is due to a single $C$ to $G$ base pair change at position 1294 in the CYP1B1 gene. This polymorphic variant may cause some altered catalytic specificity with various substrates. In particular, Leu432 variant combined with Arg48, Ser119 and Asn 453 is slightly more active (1.2- to 1.5-fold) than other CYP1B1 enzymes in carcinogen metabolism, such as benzo (a) pyrene [11]. Furthermore, previous studies suggested that the C-to-G transition resulted in an increase of p53 [12]. RsaI polymorphism located in the 5 -flanking region of the CYP2E1 was found to affect the transcriptional regulation of the gene, leading to a higher expression level of mRNA among individuals [13].

GSTs belong to a superfamily of detoxification enzymes that facilitate the inactivation of chemical carcinogens and environmental toxic compounds, such as HAAs and PAHs. GSTM1 and GSTT1 genes are polymorphic and encode the GST- $\mu$ and GST- $\theta$ enzymes respectively. For both GSTM1 and GSTT1, the "null" alleles result in a complete loss of enzyme function. SULTs, phase II enzymes with dual functions, are associated with the detoxification and activation of different carcinogens, as well as the regulation of many hormones [14]. SULT1A1 is involved in the bioactivation of HAAs and PAHs [15]. One polymorphism of SULT1A1 located in the coding region (638G to A) leads to an Arg213His amino acid change, and the variant A allele $\left(S U L T 1 A 1^{*} 2\right)$ is associated with remarkably reduced sulforansferase activity in platelets compared with the wild-type G allele (SULT1A1*1) [16].

Cigarette smoking and the aforementioned genetic polymorphisms derived from distinct pathways may be associated with CRC. However, minimal information has been previously reported about possible gene-gene and geneenvironment interactions. The present study was conducted to explore the role of interactions between ciga- rette smoking and phase I and phase II metabolic enzymes in CRC, using a nested case-only study in a Chinese Han population cohort.

\section{Methods}

\section{Study population and sample collection}

Participants in this study were selected from a CRC cohort-study population as previously reported [17]. In brief, from May 1989 to April 1990, a prospective cohort study based on a CRC survey was initiated in Jiashan County, Zhejiang province, China. The study population was defined as all residents aged 30 yrs or older in 10 small towns. All subjects were ethnic Han Chinese and residents in Jiashan County. Follow-up for the incidence of cancer in the entire cohort was established by the cancer registry system and CRC reporting system in Jiashan County. 207 individuals, who were diagnosed with CRC before May 2005, comprised the subjects in this analysis. 841 unaffected subjects who were randomly selected from the cohort population were analyzed to examine the assumption of independence between genotypes and cigarette smoking. All subjects were interviewed through a questionnaire, including demographic characteristics, smoking habits, alcohol consumption, and disease history, by professionally trained interviewers. Subjects were considered smokers if they had ever smoked at least one cigarette per day for a period of a year more. The smoking data obtained from study subjects included: the age the subject started smoking, smoking frequency, smoking duration, and inhalation for cigarette smokers. The questions on alcohol consumption included drinking status, average frequency, types of drinks, and average consumption. After informed consent was obtained from each participant, $5 \mathrm{ml}$ of blood was collected and stored at $-60^{\circ} \mathrm{C}$. The project was approved by the Medical Ethical Committee of the College of Medicine, Zhejiang University.

\section{Genotyping}

Genomic DNA was extracted using the improved salting out procedure. Di-allele -specific-amplification with artificially modified primer (di-ASA-AMP) was used to detect the genotype of CYP1B1 C1294G [18]. Two pairs of primers (P1, P2, S1 and S2) are shown in Table 1. The primers of $\mathrm{S} 2$ and $\mathrm{P} 2$ produced a band representing the $\mathrm{C}$ allele ( $370 \mathrm{bp}$ ); the other pair of primer (S1 and $\mathrm{P} 1)$ produced a band representing the $\mathrm{G}$ allele (173 bp). The outer primers (P1 and P2) produced a common band (505 bp).

GSTM1 and GSTT1 genetic polymorphisms were detected simultaneously in a single assay using a multiplex polymerase chain reaction (PCR) approach [19]. The beta-globin gene co-amplified as an internal positive control, whereas sterile $\mathrm{H} 2 \mathrm{O}$ was substituted for genomic DNA and served as a negative control. Positive and nega- 
Table I: Primers and restriction enzymes used for genotyping analyses

\begin{tabular}{lll}
\hline Gene & Primers(5'-3'; = forward, $R$ = reverse) & Restriction enzyme \\
\hline CYPIA2 C734A & F: CCC AGA AGT GGA AAC TGA GA & Apal \\
CYPIBI CI294G & R: GGG TTG AGA TGG AGA CAT TC & \\
& PI: TGT CCT GGC CTT CCT TTA TGA & - \\
& P2: GCC TCT TGC TTC TTA TTG GCA & - \\
SI: CCG GGT TAG GCC ACT TGA C & - \\
CYP2EI C-1019T & S2: GTC TGT GAA TCA TGA CCG AC & - \\
GSTMI & F: CCA GTC GAG TCT ACA TTG TCA & Rsal \\
& R: TTC ATT CTG TCT TCT AAC TGG & \\
GSTTI & F: TTC TGG ATT GTA GCA GAT CA & - \\
& R: CGC CAT CTT GTG CTA CAT TGC & - \\
S-Globin & F: GCC CTG GCT AGT TGC TGA AG & - \\
SULTIAI G638A & R: GCA TCT GAT TTG GGG ACC ACA & - \\
& F: CAA CTT CAT CCA CGT TCA CC & - \\
& R: GAA GAA CCA AGG ACA GGT AC & - \\
& F: GGT TGA GGA GTT GGC TCT GC & Hhal \\
& R: ATG AAC TCC TGG GGG ACG GT \\
\end{tabular}

tive control samples were analyzed in each experiment. PCR primers are given in Table 1.

The polymerase chain reaction-restriction fragment length polymorphism (PCR-RFLP) method was applied to detect the CYP1A2 C734A [20], CYP2E1 C-1019T [21], and SULT1A1 G638A [22] genotypes. The primers and restriction enzymes used for PCR-PFLP are shown in Table 1. Reliability and validity of the polymorphism analysis were assessed through a repeat analysis using a randomly sampled $10 \%$ of the data. No discrepancies were found in the present study.

\section{Statistical analysis}

The $\chi^{2}$-goodness-of-fit test was used to test the HardyWeinberg equilibrium. For polymorphisms with a low variant allele frequency, the homozygote for the variant allele was combined with the heterozygote, including gene CYP1B1 and SULT1A1. For certain genes, genotypes were combined on the basis of a known phenotype-genotype relationship, for instance, the combination of CYP1A2 734 CC and CA genotypes, CYP2E1 -1019 CT and TT genotypes were defined as 'poor metabolizer', while the AA genotype of CYP1A2 734 and CC genotype of CYP2E1 -1019 were termed as 'extensive metabolizer'.

In order to estimate gene-gene and gene-environment interactions, a case-only design was applied. The case-only design is an efficient way of estimating gene-gene and gene-environment interactions, but it cannot evaluate the main effect of either [23-25]. Such interactions may be obtained in a case-only design if independence between genotypes and between genotypes and environment expo- sure is assumed. Case-only odds ratios (COR) for the relevant interactions and 95\% confidence intervals (95\% CI) were estimated via unconditional logistic regression. Possible confounding variables included age, gender, cigarette smoking, and alcohol consumption. Participants with missing values for any of the variables in the regression model were omitted from the analysis.

All p-values are two-sided, and all analyses are carried out using Stata Statistical Software version 8.0.

\section{Results \\ Characteristics of patients with CRC}

The characteristics of CRC patients are shown in Table 2. $50.7 \%$ of the participants were male and $49.3 \%$ female, the mean age being 65.82 years (S.D. $=9.81$ years). The observed smoking rate (ever-smoking) was $40.6 \%$, which was lower than the rate of non-smoking (59.4\%). Among smokers, 31 presented a smoking history of more than 35 pack-years (36.9\%), and 53 presented a smoking history of more than 30 pack-years (63.1\%). Excluding one missing response, the observed drinking rate was 28.5\%, 35 patients $(60.0 \%)$ declared moderate drinkers (drink less than $50 \mathrm{~g}$ ethanol a day), and 24 patients (40\%) declared heavy drinkers.

\section{The effect of gene-gene interaction on CRC}

Table 3 presents the COR for interactions between genotypes in CRC, as determined in the case-only design. All genotype distributions conformed to Hardy-Weinberg equilibrium in this population. A significant interaction was observed between CYP1B1 1294G allele and SULT1A1 638A allele, the COR being 2.67 (95\%CI: 1.14- 
Table 2: Characteristics of CRC study patients

\begin{tabular}{lr}
\hline Gender & $105(50.7 \%)$ \\
Male & $102(49.3 \%)$ \\
Female & $28(13.5 \%)$ \\
Age (years) & $40(19.3 \%)$ \\
$<54$ & $70(33.8 \%)$ \\
$54-60$ & $69(33.3 \%)$ \\
$6 I-7 I$ & $123(59.4 \%)$ \\
$>71$ & $84(40.6 \%)$ \\
Cigarette smoking & $51(24.6 \%)$ \\
Non-smoker & $31(15.0 \%)$ \\
Smoker & $2(1 \%)$ \\
$\quad$ History (pack-years) & \\
$\quad \leq 35$ & $147(71.0 \%)$ \\
$\quad>35$ & $35(16.9 \%)$ \\
$\quad$ No response & $24(11.6 \%)$ \\
Alcohol consumption & $1(0.5 \%)$ \\
Non-drinker & \\
Moderate drinker $(<50$ g ethanol/day) & \\
Heavy drinker $(\geq 50$ g ethanol/day) & \\
No response & \\
\hline
\end{tabular}

6.27). However, COR combinations for the other genegene interactions were not significant at the five percent level.

\section{The effect of gene-environment interaction on CRC}

COR for gene-environment interactions between metabolic enzyme genotypes and cigarette smoking is shown in Table 4. Case-only analyses revealed that an interaction existed between cigarette smoking and CYP1B1 1294G allele in CRC (COR = 2.62, 95\%CI: 1.01-6.72), the COR for the interaction between CYP1B1 1294G and smoking history > 35 pack-years was 3.47 (95\%CI: 1.12-10.80). No other significant interactions between cigarette smoking and other genotypes were observed.

\section{Discussion}

Epidemiological studies suggested that gene-gene and gene-environment interactions were associated with cancer susceptibility, especially the relationship between metabolic enzyme genes and environmental carcinogens [2628]. Interactions between carcinogen-metabolizing enzymes and environmental factors may have a marked impact on the population attributable risk for cancer. Therefore, the exploration of the role of gene-gene and gene-environment interactions in low penetrance-genes may elucidate the causation of common sporadic cancers. In the present study, we examined gene-gene and geneenvironment interactions among 6 polymorphisms and cigarette smoking through a case-only design.

Few studies have described the association between genegene interactions and the risk of CRC to date. Sachse et al. [8] conducted a multicenter case-only study on 490 CRC patients and 593 controls, finding no significant interac- tions between GST and CYP1A1. However, in a recent case-control study in China, we have demonstrated that the combinations of GSTT1 and GSTM1 as well as CYP1A1*2A and GSTT1 are significantly associated with CRC [29]. Another study in Taiwan reported that the combination of CYP2E1 and GSTM1 was associated with breast cancer without the habits of cigarette smoking and alcohol consumption [30]. In contrast, we found no evidence for a significant interaction between CYP2E1 and GSTM1 as related to CRC in our study population.

It is of particular interest that we found a clear interaction between CYP1B1 1294G allele and SULT1A1 638A allele in this case-only study. This finding did not support the hypotheses based on in vitro model studies [11,16], suggesting that SULT1A1-213Arg (the 638G allele) and CYP1B1 432Val (the 1294C allele) enzyme could protect against chemical carcinogens. However, our current knowledge about biotransformation of these carcinogens by these two enzymes is based primarily on in vitro model studies, which may not reflect the complicated situation of carcinogen metabolism in vivo correctly. Bamber et al. [31] reported that a significantly reduced risk of CRC (OR $=0.47 ; 95 \% \mathrm{CI}: 0.27-0.83)$ was associated with the SULT1A1 638GG genotype in Caucasian subjects under the age of 80 . Similar findings have also been reported in the study of other cancers. Dandara et al. [32] revealed that the homozygous SULT1A1 638AA genotype was associated with increased risk for oesophageal cancer among smokers. And another study [33] on lung cancer in the Chinese population (805 cases and 809 controls) reported that the variant A allele of SULT1A1 was associated with an increased risk of lung cancer (OR, 1.85; 95\% CI, 1.44-2.37). Furthermore, these authors showed that 
Table 3: Gene-gene interactions for combinations of metabolic enzymes genotypes in CRC

\begin{tabular}{|c|c|c|c|c|c|}
\hline Genotype & CYPIA2 C734A & AA & $\mathrm{CC}+\mathrm{CA}$ & $\operatorname{COR}(95 \% \mathrm{Cl})^{*}$ & $P$-value \\
\hline \multicolumn{6}{|l|}{ GSTMI } \\
\hline Present & & 37 & 47 & I.00 (Ref.) & 0.14 \\
\hline Null & & 42 & 78 & $1.56(0.86-2.82)$ & \\
\hline \multicolumn{6}{|l|}{ GSTTI } \\
\hline Present & & 61 & 92 & I.00 (Ref.) & 0.59 \\
\hline Null & & 18 & 33 & $1.21(0.62-2.36)$ & \\
\hline \multicolumn{6}{|l|}{ SULTIAI } \\
\hline$* 1 / * 1$ & & 68 & 109 & I.00 (Ref.) & 0.86 \\
\hline \multirow[t]{2}{*}{$* 1 / * 2, * / * 2$} & & 11 & 16 & $0.93(0.40-2.15)$ & \\
\hline & CYPIBICI294G & CC & $C G+G G$ & $\operatorname{COR}(95 \% \mathrm{Cl})^{*}$ & $P$-value \\
\hline \multicolumn{6}{|l|}{ GSTMI } \\
\hline Present & & 50 & 34 & I.00 (Ref.) & 0.16 \\
\hline Null & & 78 & 40 & $0.65(0.35-1.19)$ & \\
\hline \multicolumn{6}{|l|}{ GSTTI } \\
\hline Present & & 92 & 69 & I.00 (Ref.) & 0.08 \\
\hline Null & & 36 & 15 & $0.52(0.25-1.08)$ & \\
\hline \multicolumn{6}{|l|}{ SULTIAI } \\
\hline$* 1 / * 1$ & & 117 & 59 & I .00 (Ref.) & 0.02 \\
\hline \multirow[t]{2}{*}{$* 1 / * 2, * / * 2$} & & 13 & 15 & $2.67(1.14-6.27)$ & \\
\hline & CYP2EI C-1019T & CC & $\mathrm{CT}+\mathrm{TT}$ & $\operatorname{COR}(95 \% \mathrm{Cl})^{*}$ & $P$-value \\
\hline \multicolumn{6}{|l|}{ GSTMI } \\
\hline Present & & 33 & 51 & I.00 (Ref.) & 0.23 \\
\hline Null & & 58 & 62 & $0.70(0.39-1.26)$ & \\
\hline \multicolumn{6}{|l|}{ GSTTI } \\
\hline Present & & 66 & 87 & I.00 (Ref.) & 0.42 \\
\hline Null & & 25 & 26 & $0.76(0.40-1.47)$ & \\
\hline \multicolumn{6}{|l|}{ SULTIAI } \\
\hline$* \mid / * 1$ & & 83 & 94 & 1.00 (Ref.) & 0.12 \\
\hline$* 1 / * 2, * 1 * 2$ & & 8 & 19 & $2.05(0.82-5.11)$ & \\
\hline
\end{tabular}

* Unconditional logistic regression adjusted for gender, age, cigarette smoking and alcohol consumption.

the increased risk of lung cancer related to the variant SULT1A1 genotypes was more pronounced in younger subjects and limited to smokers. A case-only study on 282 women with breast cancer found that smokers carrying the SULT1A1 638 A allele had a two-fold increase in risk compared to non-smokers carrying the SULT1A1 638GG genotype $(\mathrm{OR}=2.55,95 \% \mathrm{CI}$ : $1.21-5.36)$, and smokers carrying the CYP1B1 $1294 \mathrm{G}$ allele also had a higher risk of breast cancer than non-smokers carrying the 1294CC genotype (OR = 2.32, 95\%CI: 1.00-5.38) [34]. These findings indicated that SULT1A1 and CYP1B1, among many other metabolic pathways, may not be of importance in the metabolic activation of these carcinogens in vivo.

However, other possibilities may also exist for the explanation of our results. Accumulating evidence suggested that CRC is a hormone dependent tumor. For instance, epidemiological studies found that a correlation existed between breast cancer and colorectal cancer in women $[35,36]$. A meta-analysis of seven cohort studies demonstrated that a weak association existed between breast cancer and the subsequent risk of colorectal cancer (pooled relative risk $(R R)=1.15 ; 95 \% C I=0.99-1.31]$, and pooled results from five cohort studies showed that the risk of breast cancer after colorectal cancer was similar (pooled $\mathrm{RR}=1.10 ; 95 \% \mathrm{CI}=1.03-1.17$ ) [37]. In addition, a metaanalysis by Schoen et al. [38] indicated that women with a history of breast, endometrial, or ovarian cancer are at a statistically significant increased risk for subsequent colorectal cancer. The study of English et al. [39] indicated that the loss of estrogen inactivation may be an important mechanism in the pathogenesis of colonic cancer. The normal colonic mucosa has a high level of 17betahydroxysteroid dehydrogenase (17beta-HSD)-mediated estradiol metabolism (inactivation of estradiol to estrone), while the enzyme activity of 17beta-HSD was significantly decreased in the tumor [40]. Taken together, these findings suggest that the oestrogen metabolism in vivo might be associated with increased risk of CRC. CYP1B1 and SULT1A1 are all important estrogen-metabolizing enzymes. CYP1B1 is responsible for catalyzing the formation of 4-hydroxy-estradiol, while SULT1A1 is involved in the inactivation of these carcinogens. The variant of CYP1B1 displayed increased catalytic efficiency 
Table 4: Gene-environment interactions for combination of metabolic enzymes and cigarette smoking in CRC

\begin{tabular}{|c|c|c|c|c|c|c|c|}
\hline \multirow[t]{3}{*}{ Genotype } & \multicolumn{7}{|c|}{ Cigarette smoking } \\
\hline & \multirow[t]{2}{*}{ Non-smoker } & \multirow[t]{2}{*}{ Smoker } & \multirow[t]{2}{*}{ COR $(95 \% \mathrm{Cl}) *$} & \multicolumn{4}{|c|}{ Smoking history (pack-years) } \\
\hline & & & & $\leq 35$ & $\operatorname{COR}(95 \% \mathrm{Cl}) *$ & $>35$ & $\operatorname{COR}(95 \% \mathrm{Cl})^{*}$ \\
\hline \multicolumn{8}{|l|}{ CYPIA2 C734A } \\
\hline AA & 50 & 29 & I.00(ref.) & 17 & I.00(ref.) & 12 & I.00(ref.) \\
\hline $\mathrm{CA}+\mathrm{CC}$ & 72 & 53 & $1.04(0.44-2.50)$ & 33 & $1.13(0.42 \sim 3.01)$ & 18 & $0.95(0.3 \mid \sim 2.93)$ \\
\hline \multicolumn{8}{|c|}{ CYPIBI CI294G } \\
\hline CC & 82 & 47 & I.00(ref.) & 31 & I.00(ref.) & 16 & 1.00 (ref.) \\
\hline$C G+G G$ & 40 & 35 & $2.62(1.01-6.72)^{\#}$ & 19 & $1.92(0.72 \sim 5.1 \mathrm{I})$ & 15 & $3.47(1.12 \sim 10.80)^{\#}$ \\
\hline \multicolumn{8}{|c|}{ CYP2EI C-1019T } \\
\hline $\mathrm{CC}$ & 60 & 31 & I.00(ref.) & 18 & I.00(ref.) & 12 & I.00(ref.) \\
\hline $\mathrm{CT}+\mathrm{TT}$ & 62 & 51 & $1.83(0.76-4.40)$ & 32 & $2.42(0.91 \sim 6.46)$ & 18 & $1.49(0.49 \sim 4.53)$ \\
\hline \multicolumn{8}{|l|}{ GSTMI } \\
\hline Present & 52 & 32 & I.00(ref.) & 19 & I.00(ref.) & 12 & I.00(ref.) \\
\hline Null & 70 & 50 & $1.53(0.62-3.75)$ & 31 & $1.45(0.55 \sim 3.83)$ & 18 & $1.77(0.58 \sim 5.44)$ \\
\hline \multicolumn{8}{|l|}{ GSTTI } \\
\hline Present & 94 & 59 & I.00(ref.) & 36 & I.00(ref.) & 21 & I.00(ref.) \\
\hline Null & 28 & 23 & $1.32(0.49-3.5 \mathrm{I})$ & 14 & $1.4 \mathrm{I}(0.49 \sim 4.10)$ & 9 & $1.79(0.53 \sim 6.10)$ \\
\hline \multicolumn{8}{|l|}{ SULTIAI } \\
\hline$* \mathrm{I} / * \mathrm{I}$ & 106 & 72 & I.00(ref.) & 45 & I.00(ref.) & 25 & 1.00 (ref.) \\
\hline$* 1 / * 2, * 2 / * 2$ & 17 & 11 & $0.53(0.16-1.69)$ & 5 & $0.4 \mathrm{I}(0.1 \mathrm{I} \sim \mathrm{I} .60)$ & 6 & $0.65(0.16 \sim 2.66)$ \\
\hline
\end{tabular}

* Unconditional logistic regression adjusted for gender, age and alcohol consumption; \# $\mathrm{P}<0.05$

compared to the wild-type enzyme, and may be associated with significant changes in oestrogen metabolism. The combination of the CYP1B1 1294G allele and the SULT1A1 638A allele with modified ability to metabolize estrogens could increase the level of estrogen (i.e., 4hydroxy-estradiol), which may finally result in a differential susceptibility to CRC.

Our gene and environment combined analyses suggested that a significant interaction, which may increase the risk for CRC, exists between the CYP1B1 1294G allele and cigarette smoking. This finding also did not support the hypothesis based on in vitro model studies [11], and no reports have described the association between this geneenvironment interaction and CRC risk to date. However, the same gene-environment interaction was reported in studies on other cancers, the results of which were similar to ours. Liang et al. [18] found that CYP1B1 432Val polymorphism may modulate individual susceptibility to lung cancer among smokers in the Chinese population (OR: 2.78, 95\%CI: 1.46-5.29). A case-only study on breast cancer also reported that the combination of cigarette smoking and CYP1B1 1294G allele was associated with a higher risk of breast cancer [34]. Taken together, in contrast to the hypothesis based on the in vitro model studies, these findings suggest that the 1294CC genotype may protect against chemical carcinogens related to certain human cancers, such as PAHs. In addition, whether tobacco contains numerous carcinogens and compound(s) that assur- edly cause human CRC still remains to be seen. Further studies are needed to address these possibilities.

A few case-control studies have been published with regard to the combination of GSTT1/GSTM1 and cigarette smoking in association with CRC. A study of 952 rectal cancer cases and 1205 controls in the United States found that a borderline significant interaction existed between the GSTM1 null allele and cigarette smoking [41]. Another cohort study on smoking with a nested case-only design also found a borderline significant interaction between GSTM1 null and cigarette smoking [42]. However, two studies indicated that no significant interactions between GSTT1/GSTM1 and cigarette smoking were observed $[43,44]$, the results of which were similar to ours. Larger studies are needed to explore the interactions between the susceptible genes and smoking and to identify the underlying mechanisms of CRC.

One of the limitations of the case-only design is that, in order to obtain gene-gene and gene-environment interactions, independence between genotypes and between genotypes and environment exposure must be assumed. In this study, we validated this independence assumption through the analysis of a relatively large number of healthy subjects $(\mathrm{n}=841,62.55 \pm 10.85$ years $)$ randomly selected from the same cohort population. Another limitation of the current study is that selection bias might occur from all patients being cancer survivors at the time 
of analysis. However, since we used incident cases recruited from the cohort population, our findings are unlikely to be attributable to selection bias.

\section{Conclusion}

Our results showed that the interaction between polymorphisms in CYP1B1 1294G and SULT1A1*2 play a significant role on CRC in Chinese people, and the association between cigarette smoking and CRC can be differentiated by the CYP1B1 1294G allele. However, these preliminary exploratory results should be confirmed in larger studies.

\section{Competing interests}

The author(s) declare that they have no competing interests.

\section{Authors' contributions}

CF participated in the design of the study, SNP genotyping, and drafted the manuscript. KC conceived of the study, and participated in its design and coordination. MJ, YZ and SZ participated in data collection and performed the statistical analysis. BL participated in SNP genotyping. All authors read and approved the final manuscript.

\section{Acknowledgements}

We would like to thank all the members of the Institute of Cancer Research and Prevention of Jiashan County for assistance with data collection. This work was supported by a grant from China National Science Fund Council (NSFC 3047I492).

\section{References}

I. Parkin DM, Bray F, Ferlay J, Pisani P: Global cancer statistics, 2002. CA Cancer J Clin 2005, 55:74-108.

2. You WC, Jin F, Devesa S, Gridley G, Schatzkin A, Yang G, Rosenberg $P$, Xiang YB, Hu YR, Li Q: Rapid increase in colorectal cancer rates in urban Shanghai, 1972-97, in relation to dietary changes. J Cancer Epidemiol Prev 2002, 7:143-146.

3. American Cancer Society: Colorectal cancer facts $\&$ figures special edition 2005. Atlanta: American Cancer Society 2005.

4. Gertig DM, Hunter DJ: Genes and the environment in the etiology of colorectal cancer. Semin Cancer Biol 1998, 8:285-298.

5. Giovannucci E: An updated review of the epidemiological evidence that cigarette smoking increases risk of colorectal cancer. Cancer Epidemiol Biomarkers Prev 200I, 1 0:725-731.

6. Chao A, Thun MJ, Jacobs EJ, Henley SJ, Rodriguez C, Calle EE: Cigarette smoking and colorectal cancer mortality in the cancer prevention study II. I Natl Cancer Inst 2000, 92: I888-1896.

7. Mizoue T, Inoue M, Tanaka K, Tsuji I, Wakai K, Nagata C, Tsugane S: Tobacco smoking and colorectal cancer risk: an evaluation based on a systematic review of epidemiologic evidence among the Japanese population. Jpn J Clin Oncol 2006, 36:25-39.

8. Sachse C, Smith G, Wilkie MJ, Barrett JH, Waxman R, Sullivan F, Forman D, Bishop DT, Wolf CR, Colorectal Cancer Study Group: A pharmacogenetic study to investigate the role of dietary carcinogens in the etiology of colorectal cancer. Carcinogenesis 2002, 23: 1839-1849.

9. Shimada T, Hayes CL, Yamazaki H, Amin S, Hecht SS, Guengerich FP, Sutter TR: Activation of chemically diverse procarcinogens by human cytochrome P-450 IB I. Cancer Res 1996, 56:2979-2984.

10. Sachse C, Brockmoller J, Bauer S, Roots I: Functional significance of a C--> A polymorphism in intron I of the cytochrome P450 CYPIA2 gene tested with caffeine. Br J Clin Pharmacol 1999, 7:445-449.

II. Shimada T, Watanabe J, Inoue K, Guengerich FP, Gillam EM: Specificity of I 7 beta-oestradiol and benzo[a]pyrene oxidation by polymorphic human cytochrome P450 IB I variants substituted at residues 48, II 9 and 432. Xenobiotica 200I, 3I: I63-I76. 12. Ko Y, Abel J, Harth V, Brode P, Antony C, Donat S, Fischer HP, OrtizPallardo ME, Thier R, Sachinidis A, Vetter H, Bolt HM, Herberhold C, Bruning T: Association of CYPI B I codon 432 mutant allele in head and neck squamous cell cancer is reflected by somatic mutations of p53 in tumor tissue. Cancer Res 200I, 61:4398-4404.

13. Watanabe J, Hayashi S, Kawajiri K: Different regulation and expression of the human CYP2EI gene due to the Rsal polymorphism in the 5'-flanking region. J Biochem (Tokyo) 1994, I 16:321-326.

14. Glatt H, Meinl W: Pharmacogenetics of soluble sulfotransferases (SULTs). Naunyn Schmiedebergs Arch Pharmacol 2004, 369:55-68.

15. Glatt $\mathrm{H}$ : Sulfation and sulfotransferases 4: bioactivation of mutagens via sulfation. FASEB J 1997, I I:3 |4-32I.

16. Engelke CE, Meinl W, Boeing H, Glatt H: Association between functional genetic polymorphisms of human sulfotransferases IAI and IA2. Pharmacogenetics 2000, 10:163-169.

17. Zheng S, Chen K, Liu X, Ma X, Yu H, Chen K, Yao K, Zhou L, Wang $L$, Qiu P, Deng $Y$, Zhang S: Cluster randomization trial of sequence mass screening for colorectal cancer. Dis Colon Rectum 2003, 46:5I-58.

18. Liang G, Pu Y, Yin L: Rapid detection of single nucleotide polymorphisms related with lung cancer susceptibility of Chinese population. Cancer Lett 2005, 223:265-274.

19. Abdel-Rahman SZ, el-Zein RA, Anwar WA, Au WW: A multiplex PCR procedure for polymorphic analysis of GSTMI and GSTTI genes in population studies. Cancer Lett 1996, 107:229-233.

20. Cornelis MC, El-Sohemy A, Campos H: Genetic polymorphism of CYPIA2 increases the risk of myocardial infarction. J Med Genet 2004, 41:758-762.

21. Hildesheim A, Chen CJ, Caporaso NE, Cheng YJ, Hoover RN, Hsu MM, Levine PH, Chen IH, Chen JY, Yang CS: Cytochrome P4502EI genetic polymorphisms and risk of nasopharyngeal carcinoma: results from a case-control study conducted in Taiwan. Cancer Epidemiol Biomarkers Prev 1995, 4:607-610.

22. Peng CT, Chen JC, Yeh KT, Wang YF, Hou MF, Lee TP, Shih MC, Chang JY, Chang JG: The relationship among the polymorphisms of SULTIAI, IA2 and different types of cancers in Taiwanse. Int J Mol Med 2003, I I:85-89.

23. Piegorsch WW, Weinberg CR, Taylor JA: Non-hierarchical logistic models and case-only designs for assessing susceptibility in population-based case-control studies. Stat Med 1994, 13:153-162.

24. Yang Q, Khoury MJ, Sun F, Flanders WD: Case-only design to measure gene- gene interaction. Epidemiology 1999, 10:167-170.

25. Hamajima N, Yuasa H, Matsuo K, Kurobe Y: Detection of geneenvironment interaction by case-only studies. Jpn J Clin Oncol 1999, 29:490-493.

26. Giarelli E, Jacobs LA: Modifying cancer risk factors: the geneenvironment interaction. Semin Oncol Nurs 2005, 21:27I-277.

27. Kotnis A, Sarin R, Mulherkar R: Genotype, phenotype and cancer: Role of low penetrance genes and environment in tumour susceptibility. J Biosci 2005, 30:93-102.

28. Mucci LA, Wedren S, Tamimi RM, Trichopoulos D, Adami HO: The role of gene-environment interaction in the aetiology of human cancer: examples from cancers of the large bowel, lung and breast. J Intern Med 200I, 249:477-493.

29. Fan $\mathrm{CH}$, Jin MJ, Zhang $Y$, Song L, Xu H, Jiang QT, Yu WP, Chen K: Association between genetic polymorphisms of metabolic enzymes and susceptibility of colorectal cancer. Zhonghua $Y_{u}$ Fang Yi Xue Za Zhi 2006, 40:13-17. Chinese.

30. Wu SH, Tsai SM, Hou MF, Lin HS, Hou LA, Ma H, Lin JT, Yeh FL, Tsai LY: Interaction of genetic polymorphisms in cytochrome P450 2EI and glutathione S-transferase MI to breast cancer in Taiwanese woman without smoking and drinking habits. Breast Cancer Res Treat 2006, 100:93-98.

3I. Bamber DE, Fryer AA, Strange RC, Elder JB, Deakin M, Rajagopal R, Fawole A, Gilissen RA, Campbell FC, Coughtrie MW: Phenol sulphotransferase SULTIAI*I genotype is associated with reduced risk of colorectal cancer. Pharmacogenetics 200I, I I:679-685. 
32. Dandara C, Li DP, Walther G, Parker MI: Gene-environment interaction: the role of SULTIAI and CYP3A5 polymorphisms as risk modifiers for squamous cell carcinoma of the oesophagus. Carcinogenesis 2006, 27:79|-797.

33. Liang G, Miao X, Zhou Y, Tan W, Lin D: A functional polymorphism in the SULTIAI gene (G638A) is associated with risk of lung cancer in relation to tobacco smoking. Carcinogenesis 2004, 25:773-778.

34. Saintot M, Malaveille C, Hautefeuille A, Gerber M: Interactions between genetic polymorphism of cytochrome P450-IBI, sulfotransferase IAI, catechol-o-methyltransferase and tobacco exposure in breast cancer risk. Int J Cancer 2003, 107:652-657.

35. Toma S, Giacchero A, Bonelli L, Graziani A, De Lorenzi R, Aste H: Association between breast and colorectal cancer in a sample of surgical patients. Eur J Surg Oncol 1987, 13:429-432.

36. Neugut Al, Murray TI, Lee WC, Robinson E: The association of breast cancer and colorectal cancer in men. An analysis of surveillance, epidemiology, and end results program data. Cancer 1991, 68:2069-2073.

37. Eisen GM, Sandler RS: Are women with breast cancer more likely to develop colorectal cancer? Critical review and meta-analysis. J Clin Gastroenterol 1994, 19:57-63.

38. Schoen RE, Weissfeld JL, Kuller LH: Are women with breast, endometrial, or ovarian cancer at increased risk for colorectal cancer? Am J Gastroenterol 1994, 89:835-842.

39. English MA, Kane KF, Cruickshank N, Langman MJ, Stewart PM, Hewison M: Loss of estrogen inactivation in colonic cancer. J Clin Endocrinol Metab 1999, 84:2080-2085.

40. English MA, Stewart PM, Hewison M: Estrogen metabolism and malignancy: analysis of the expression and function of I7beta-hydroxysteroid dehydrogenases in colonic cancer. Mol Cell Endocrinol 200I, I 1 I:53-60.

4I. Slattery ML, Edwards S, Curtin K, Schaffer D, Neuhausen S: Associations between smoking, passive smoking, GSTM-I, NAT2, and rectal cancer. Cancer Epidemiol Biomarkers Prev 2003, | 2:882-889.

42. Luchtenborg M, Weijenberg MP, Kampman E, van Muijen GN, Roemen GM, Zeegers MP, Goldbohm RA, van't Veer P, de Goeij AF, van den Brandt PA: Cigarette smoking and colorectal cancer: APC mutations, hMLHI expression, and GSTMI and GSTTI polymorphisms. Am J Epidemiol 2005, 161:806-8I5.

43. Gertig DM, Stampfer M, Haiman C, Hennekens CH, Kelsey K, Hunter DJ: Glutathione S-transferase GSTMI and GSTTI polymorphisms and colorectal cancer risk: a prospective study. Cancer Epidemiol Biomarkers Prev 1998, 7:1001-1005.

44. Smits KM, Gaspari L, Weijenberg MP, Dolzan V, Golka K, Roemer HC, Nedelcheva Kristensen V, Lechner MC, Mehling GI, Seidegard J, Strange RC, Taioli E: Interaction between smoking, GSTMI deletion and colorectal cancer: results from the GSEC study. Biomarkers 2003, 8:299-3I0.

\section{Pre-publication history}

The pre-publication history for this paper can be accessed here:

http://www.biomedcentral.com/1471-2407/7/115/pre pub

\section{Publish with Biomed Central and every scientist can read your work free of charge}

"BioMed Central will be the most significant development for disseminating the results of biomedical research in our lifetime. "

Sir Paul Nurse, Cancer Research UK

Your research papers will be:

- available free of charge to the entire biomedical community

- peer reviewed and published immediately upon acceptance

- cited in PubMed and archived on PubMed Central

- yours - you keep the copyright

Submit your manuscript here:

http://www.biomedcentral.com/info/publishing_adv.asp
Biomedcentral 